\title{
LA PUBLICIDAD DE LA PLUMA ESTILOGRÁFICA
}

\section{ADVERTISING FOUNTAIN PEN}

\section{AUTORES}

Rafael Ibáñez Rojo: Profesor Ayudante Doctor. Departamento de Sociología. Facultad de Ciencias Económicas y Empresariales. Universidad Autónoma de Madrid (España).

rafael.ibañez@mixmail.com

\section{CURRÍCULUM VITAE}

Profesor Ayudante Doctor. Departamento de Sociología. Facultad de Ciencias Económicas y Empresariales. Universidad Autónoma de Madrid (España).

\section{RESUMEN}

Debemos tener desde un comienzo presente que la pluma estilográfica no se adapta adecuadamente a las fases más o menos ideales del desarrollo de la sociedad de consumo en España. Se trata de un producto de uso cotidiano con anterioridad incluso a la aparición del lenguaje publicitario por lo que no requiere ser introducido artificialmente. Su evolución como objeto de consumo responde a características peculiares y específicas (por ejemplo la expansión del bolígrafo) y aunque, como para todo el mundo del consumo, la década de los sesenta es fundamental lo será por motivos diferentes.

\section{PALABRAS CLAVE}

Publicidad - Pluma estilográfica - Publicidad 


\begin{abstract}
We have from the beginning in mind that the pen is not adapted adequately to the stage more or less ideal for the development of consumer society in Spain. This is an everyday product even before the appearance of advertising language so need not be introduced artificially. His evolution as a consumer object responds to specific and unique characteristics (eg the expansion of the pen) and although, as for all the world of consumption, the sixties is essential it will be for different reasons.
\end{abstract}

\title{
KEY WORDS
}

Advertising - Fountain Pen - Advertising

Debemos tener desde un comienzo presente que la pluma estilográfica no se adapta adecuadamente a las fases más o menos ideales del desarrollo de la sociedad de consumo en España. Se trata de un producto de uso cotidiano con anterioridad incluso a la aparición del lenguaje publicitario por lo que no requiere ser introducido artificialmente. Su evolución como objeto de consumo responde a características peculiares y específicas (por ejemplo la expansión del bolígrafo) y aunque, como para todo el mundo del consumo, la década de los sesenta es fundamental lo será por motivos diferentes.

Por otro lado, no se trata de un producto de abundante publicidad salvo en el periodo de Navidad al ser frecuentemente objeto de regalo. Con la documentación recogida no se ha pretendido, por tanto, realizar una lectura profunda de los 
significados encerrados detrás de los complejos significantes, especialmente de los últimos años. El mayor énfasis ha tratado de realizarse en los cambios del discurso y la imagen publicitaria para ponerlos en relación con los cambios sociales de los consumidores objetivos del producto. La amplitud del periodo abarcado, desde la mitad de los años veinte hasta la actualidad, permite hacer un recorrido sencillo por algunas de las líneas de fractura que definen los periodos históricos en la historia de la sociedad española. Los límites de los cambios a los que haremos referencia son los límites de los grupos sociales a los que se dirige la publicidad aquí comentada. Se trata de un producto de una amplitud limitada cuya publicidad nunca pretenderá acercarse a sectores muy amplios de la sociedad.

\section{ANTES DE LA GUERRA}

Hay que ser conscientes de que la pluma constituye prácticamente el único medio de escritura generalizado hasta los años cincuenta en que irrumpe el bolígrafo. Sin embargo, la publicidad de la pluma de lujo, de la compañera fiel, como será presentada desde un comienzo, mantiene una línea de continuidad puesto que desde los años en los que hemos recogido documentación la pluma común o bien no se anuncia (como en la actualidad ocurre con los bolígrafos) o bien se manifiesta en una publicidad muy diferente.

En general, durante los años previos a la guerra civil la pluma es un producto poco publicitado y el contexto de su utilización lo explica. O bien es un producto de uso corriente, constantemente renovado en las tiendas del barrio, o bien es un producto artesanal de alta calidad para hombres de negocios y terratenientes que la unen al resto de su indumentaria distintiva. Es muy difícil rastrear en estos años la siempre estrecha relación entre la pluma de lujo y los altos negocios -sí trataremos de ejemplificarlo en años posteriores-. 
Ahora bien, dentro de la pluma de precio elevado cabe diferenciar dos subgrupos. El primero (representado ya por Sheaffer's) se define por su carácter exclusivo y de difícil acceso para la inmensa mayoría ("Decídase siempre por lo más selecto" Sheaffer's, 1927-). Son productos para toda la vida (así lo atestigua la línea LIFETIME de Sheaffer's) que acompañarán siempre al consumidor (que no puede ser definido todavía como tal). Además, añaden una dimensión más, presente hasta la actualidad, la de la riqueza visual y alegórica de su publicidad. Si bien todas las plumas reclaman su estilo, en esta gama alta no se trata tanto de estilo como de arte. Desde este nivel el arte remite por un lado a lo elitista, a lo artesanal de tiempos anteriores a la producción masiva de la industrialización. Pero, por otro lado más importante, a la creación, a un individuo autónomo capaz de definir su destino y de dejar su impronta, su marca en aquello que hace, por eso no es una pluma para utilizar en tareas rutinarias. Son plumas para utilizar con los eventos y personas importantes en la vida.

El segundo subgrupo está representado por el resto de anuncios de este periodo (Conklin, Parker,...) y su configuración simbólica es bien diferente. En primer lugar, no son reacios a incorporar las características técnicas de la pluma, es decir, se definen como producto industrial, en constante renovación técnica (como muestran los anuncios de Conklin sobre el nuevo cartucho transparente de gran capacidad). Como producto industrial no renuncia a señalar la perfección téncica que preside su fabricación, la pluma aparece como un producto moderno, y la modernidad reúne durabilidad, belleza y utilidad práctica (Aurora, 1931), e implica eficiencia y belleza de líneas (Parker, 1931). Esta insistencia en la modernidad del diseño y las características del producto puede considerarse incluso adelantada si la comparamos con el resto de los productos puesto que la verdadera irrupción de lo moderno no tendrá lugar hasta que en los años sesenta se introduzcan los electrodomésticos para el hogar. En segundo lugar, tampoco tienen problemas en incorporar el precio (algo 
indiferente en el primer grupo), y con ello pretenden enfatizar no su carácter exclusivo sino el hecho de ser plumas utilizadas de forma masiva ("La pluma elegida 26 millones de veces -Parker, 1931-). En tercer lugar, la pluma es un instrumento de trabajo, también algo radicalmente diferente de lo que pretendía ser el grupo anterior. Ligada al hombre de oficina, la pluma es una compañera leal de la persona trabajadora (Conklin, 1925), una herramienta de la que siempre se puede fiar (Swan, 1927).

Apenas es necesario mencionar que la pluma se define como producto para hombres (nunca aparecerá una mujer en el anuncio), con independencia de que en el nivel de su utilidad práctica puedan aparecer gamas especialmente orientadas para la mujer (así la gama "Lady" de Parker, 1931).

Una lectura social sencilla de esta primera división que hemos trazado supone remitir el segundo grupo a la pequeña burguesía de las profesiones liberales y los puestos burocráticos tanto de empresas grandes como del Estado. Son sin duda alguna el grupo modernizador, consciente de su carácter ya relativamente masivo (en comparación la a gran burguesía y los terratenientes) y en expansión. La pluma de la gama superior es un referente simbólico al que no se renuncia. De hecho, la publicidad de esta gama está también destinada a la pequeña burguesía y las profesiones liberales, puesto que sus significantes (su carácer artístico, visual, creador, rompedor, no burocrático, no rutinario, indiferente al gasto,...) se ofrecen como marcas de una situación social diferente que el pequeño burgués admira (o es posible que admire). Esta sencilla dualización de la publicidad del producto encaja perfectamente con lo que ocurre con un amplio conjunto de productos en estas décadas. Coches, perfumes, ropa,... tienen un sector social de la gran burguesía y los grandes propietarios y otro sector de la pequeña y mediana burguesía con unas distancias considerables entre ellos, hasta el punto de configurar de forma generalizada dos discursos publicitarios diferentes. 
En último lugar, es necesario señalar que la publicidad de este periodo es una publicidad casi exclusivamente del producto. La diferenciación entre las marcas se realiza por las características técnicas del producto y no por una imagen simbólica.

\section{SILENCIO Y RENACER}

Tras la guerra civil y a lo largo de todos los años cuarenta la publicidad de la pluma se hace marginal como la de tantos otros productos. Sólo a partir de los años cincuenta hace su aparición ocupando un espacio relativamente importante en la prensa de alta difusión (por ejemplo ABC, La Vanguardia Española o Blanco y Negro). Ello no quiere decir que la pluma de alta calidad no fuera objeto común en el comercio ilegal (imágenes como las retratadas en la película La Colmena quizá fueran frecuentes), pero eso no es algo que podamos analizar.

Sin embargo, la reaparición en los cincuenta tiene lugar sin el mismo sistema de marcas, ya relativamente complejo, de los años anteriores a la guerra. Como corresponde a los años previos a los Planes de Estabilización la pluma más anunciada es de una marca española (Super T) mientras que la variedad de plumas de los años anteriores a la guerra se ha reducido notablemente. La publicidad sigue evolucionando lentamente, las anuncios recogidos en la documentación son escasos porque son un modelo que se repite durante años prácticamente sin variaciones (en el caso de Super T y Parker).

La gama más alta del producto, el consumo elitista presente en el periodo anterior ha desaparecido. Pese a la escasa documentación y con las excepciones siempre presentes se puede considerar que estos años están presididos por una tendencia al centro del mercado, por una cierta homogeneización. Ciertas características del 
producto siguen presentes puesto que la caracterizan con independencia de la marca. Siempre se reclamará su finura, su durabilidad, su facilidad de escritura y su estilo, la elegancia de líneas. Todo ello dentro de este sector medio -para el mercado de las plumas-, puesto que para el segmento de mercado más elevado todas estas características se dan por supuestas y el lenguaje publicitario no les presta atención, pero eso es algo que todavía apenas se puede apreciar en este periodo.

En estos años predominan los anuncios descriptivos y los significantes son los tópicos que corresponden al contexto económico y social del momento. En primer lugar, la apelación a lo nuevo, más presente que nunca. Pero esta forma de reivindicar un modelo como nuevo es diferente de la forma en que era realizado en el periodo anterior. Antes se subrayaba la innovación técnica, las mejoras en la construcción y los nuevos inventos. Ahora este reclamo permanece tan vivo como antes pero se ha añadido una nueva dimensión a "lo nuevo" ausente antes, ahora lo nuevo es un nuevo modelo. El nuevo modelo suele ir acompañado de alguna innovación técnica -normalmente aparente- pero esta dimensión ha pasado a ser marginal frente a la línea, la suavidad, el color. En segundo lugar, aparecen nuevos materiales que se reclaman de la misma calidad, particularmente el plástico (Super T, 1957). Esto implica cierta aceptación de la producción en serie, cierto y progresivo abandono del desprecio de toda forma de producción no artesanal. Ese proceso es paralelo a la imposición, especialmente desde la segunda mitad de los cincuenta, del american way of life que hace que Waterman's se definiera ya como "La gran marca americana" (1958) -algo inconcebible en la década anterior. En tercer lugar, el carácter homogeneizador de la propia publicidad se compensa, contradictoriamente, con la señal de la distinción. Con el carácter explícito desde el que lo podemos leer en la actualidad: "Poseer una Parker es señal de distinción" (1952); este consumo de las florecientes clases medias necesita de productos diferenciadores pero sin la necesidad de una estética semejante a la de los años anteriores a la guerra. Se prefiere el diseño ultramoderno (Parker, 1952) y la solidez y sobriedad (Mont Blanc, 1952). 
Este periodo puede leerse como precursor de lo que será ya la línea de la publicidad durante las décadas recientes. Si bien arrastra el lenguaje descriptivista y referencial hoy abandonado casi por completo -en este producto- la novedad es que la pluma ya se está convirtiendo en un fetiche, está pasando a ocupar un lugar en el espacio central -tanto en el espacio físico del anuncio como en el espacio de aquello que el anuncio representa-. El objeto pluma comienza a levantarse y sobresalir del propio anuncio, empieza a situarse más allá de todo lo que se diga sobre ella en el anuncio, lo cual abre la posibilidad de que las palabras se hagan muy pequeñas, casi insignificantes, o desaparezcan por completo -en años posteriores-(Mont Blanc, 1952; Parker, 1957).

Los años cincuenta se cierran con la expansión definitiva del bolígrafo. Las consecuencias para la utilización cotidiana de la pluma son evidentes. Sin embargo, pronto aparecerán como productos compatibles con las plumas de alta calidad. La ofensiva del bolígrafo, como recogen los dos anuncios recogidos como ejemplo (BIC, 1958), se dirige al mundo del trabajo. Habrá, por tanto, un efecto inmediato sobre la pluma estilográfica desplazándola hacia el mundo privado, hacia las relaciones personales e íntimas, hacia las ocasiones especiales, hacia la confesión de lo íntimo. Este desplazamiento y reducción en la esfera de utilización de la pluma será fundamental para la publicidad de los años posteriores.

En definitiva, se trata de un periodo contradictorio, en el que se percibe la supervivencia de significantes de la aristocracia, con el periodo del hambre todavía no superado, unidos a significantes modernizadores, industriales y de la abundancia. La diferenciación de marcas es tímida, todavía es un sistema poco diferenciado puesto que lo que distingue es la posesión de la pluma con bastante independencia de la marca de la misma. 


\section{NUEVOS ESPACIOS}

Son los años del verdadero despegue de la sociedad de consumo de masas en España. Son tiempos de ruptura con el pasado, de alabanza hacia lo artificial y negación de lo tradicional, natural y rural. Se trata también del periodo de introducción masiva de los bienes de consumo duradero y la aparición de las agencias de marketing. Sin embargo, el contexto de esta década fundamental para la constitución de la sociedad de consumo en España, no permite por sí solo leer adecuadamente la publicidad de la pluma estilográfica de la década. Tendremos que tener presente el desplazamiento en los usos de la pluma derivados de la generalización del bolígrafo.

En general, permanece el carácter genérico del consumidor, la impersonalización del discurso publicitario, mientras en otros productos ya ha aparecido el Usted. Sin embargo, ya empiezan a surgir los grandes surtidos, la variedad para que cada consumidor pueda encontrar exactamente lo que desea: "En la nueva Pelikan puede escoger entre un completo surtido de plumillas y, una vez hallada la «suya», escribirá Vd. verdaderamente a gusto" (Pelikan, 1965).

Si bien la lógica de las clases medias, el cuerpo social fundamental para explicar la expansión del consumo, parece ser la de la distinción cuando nos referimos a un amplio conjunto de productos cuyo consumo se generaliza en estos diez años, tal lógica no puede ser aplicada en el mismo sentido para el consumo de la pluma estilográfica. Desde esta perspectiva la compra de una pluma de marca comporta una mayor ambigüedad y, más que una lógica de separación y diferenciación, adquiere una dimensión de incorporación. Con esto pretendemos señalar lo que recoge un anuncio de 1969: "Sea quien sea tiene su Parker". 
Si bien en los años anteriores subsistía una cierta contradicción y conflicto entre lo español y lo extranjero, entre lo artesanal y lo masivo e indiferenciado, en este nuevo periodo, en el que tiene lugar la consolidación de la industrialización y con ella de la norma de consumo obrera, estas contradicciones se van a resolver rápidamente hacia lo extranjero e industrial-masivo. Pero esto no es un cambio muy importante para el producto aquí analizado puesto que, como hemos visto, la dimensión técnica y modernizadora la incorpora desde décadas atrás.

Pese a que el bolígrafo ya ha sustituido plenamente a la pluma en muchos ámbitos de su uso no puede considerarse que en los sesenta se produzca un cambio radical en el lenguaje de la publicidad de la pluma estilográfica. Pero sí habrá cambios fundamentales en los espacios a los que se dirige la publicidad. La pluma empieza a convertirse en parte de la personalidad, a configurar la identidad. Proceso que tiene lugar dentro de ese peculiar desplazamiento hacia el mundo íntimo y privado que ha tenido lugar por la expansión del bolígrafo.

Es aquí donde se inserta una de las características fundamentales del periodo. Este desplazamiento de los espacios de utilización de la pluma estilográfica no se realiza sólo sobre espacios ya existentes sino que la publicidad intenta crear momentos o contextos en los que debe usarse la pluma. Se trata de crear nuevas prácticas asociándolas a determinadas formas de vida. En este sentido dos anuncios son paradigmáticos para reflejar la creación de espacios en los que se hace necesario utilizar una pluma adecuada. Ambos se refieren al mundo de lo personal como ya hemos señalado:

"Actualmente utiliza Vd. con frecuencia un bolígrafo. Resulta ideal para anotaciones rápidas. Para firmar o para sus cartas peronales desea usted, sin embargo, una plumilla elástica. La plumilla que su mano necesita" (Pelikan, 1965). 
Usted desea y necesita en ese ámbito especial el uso de la pluma para marcar la diferencia, porque la pluma "reflejará su personalidad" (Inoxcrom, 1965). Son dos aspectos paralelos de un mismo desplazamiento del consumo: hacia aquel sector de productos que permiten reflejar lo diferente de la personalidad del consumidor; hacia contextos delicados, allí donde el consumidor refleja realmente quién es.

\section{AÑOS SETENTA Y OCHENTA}

Tiene lugar ahora un salto radical en las imágenes de la publicidad de las plumas. Bruscamente, un solo tipo de anuncio se ha impuesto a todas las marcas -que sólo podrán diferenciarse en el texto-, un tipo de imgen en la que la pluma flota sobre un fondo vacío. La pluma se convierte en un objeto bello en sí, que simplemente por su belleza es deseado: "Finalmente siente felicidad al tener en la mano un objeto de escritura simplemente bello" (Dupont, 1980).

El objeto pluma consolida dos dimensiones que nos permiten leer múltiples significantes de su publicidad. Por un lado, el objeto ya hemos comentado que se ha desplazado hacia lo personal e íntimo por lo que su contemplación y uso han de ser también un placer privado, el deleite puede ser en solitario. Pero, por otro lado, es un objeto para ser mostrado, no ante cualquiera, como señal de distinción. Estas dos dimensiones tratan de conjugarse en muchos de los mensajes publicitarios.

Tiene lugar un retorno a la reivindicación de lo artesanal (Sheaffer, 1973). Pero más allá de lo artesanal, en este periodo la pluma se define como obra de arte: "se necesitan más de 500 operaciones distintas y seis meses de trabajo para crear un solo encendedor" (Dupont, 1981); o "es tan perfecta que sólo accede al mercado después de pasar, satisfactoriamente, 131 controles distintos de precisión" (Parker, 1984). Además, lo que se hace con una pluma se convierte en una obra maestra (Parker, 
1984). Si la pluma ya aparece como una obra de arte, coherentemente, los anuncios evolucionarán hasta adoptar la estructura y composición de un cuadro. A la vez que como obra de arte, en una dimensión ligeramente diferente, también se pretende definir como joya. Los materiales pueden venir de China (Dupont, 1977) o de Suiza (Madison, 1977) pero todos ellos son exclusivos, no los tiene nadie, solo usted.

Frente al consumidor genérico de décadas pasadas se repiten ya las apelaciones al usted: "Signo inconfundible de que Usted tiene la mejor pluma" (Sheaffer, 1973). La referencia a los demás, la invitación a comparar, se inserta en el hecho de que ya todos tenemos pluma, ahora usted tiene que tenerla mejor que el otro. Esta es la segunda dimensión del mensaje comentada más arriba, la dimensión en la que la pluma se constituye como objeto para ser mostrado, para ser visto y admirado por los demás.

Otro proceso de este largo periodo es aquél por el cual el objeto pluma es definitivamente fetichizado, situado en el centro mismo articulando toda la composición del anuncio. Las personas -visibles en anteriores décadas- han desaparecido. Ello va a provocar que, consolidado el uso del producto y construidas unas prácticas de utilización del mismo, se consolide en estos años un sistema complejo de marcas en el que ya no basta con el oro y la plata sino que desde ahora hace falta un nombre, una imagen de marca: "Nuestro nombre es la garantía de nuestros productos" (Dunhill, 1977). Si las personas han desaparecido es porque se han espiritualizado, es porque la pluma está en el ámbito de la personalidad -tal y como se constituyó como espacio complementario al del bolígrafo-. Puede aparecer de fondo una persona, su mirada, su expresión, su carácter, porque eso es lo que será su pluma: "Esta estilográfica tiene una historia, la de usted" (Dupont, 1979). 
La pluma trata de definirse como un medio para la expresividad, como el mejor instrumento para poner nuestra marca en las cosas que hacemos. Los ejemplos son múltiples:

- "expresión de integridad" (MontBlanc, 1986).

- "Pon tu marca con un Parker". Una pluma Parker es la "manera más brillante de ofrecer la mejor imagen de uno mismo" (Parker 1984).

- "Sheaffer da carácter a tu estilo" (1986).

La pluma es el objeto que nos permite expresar lo que somos, facilita que fluyan las palabras que nos permiten comunicar a quien queremos lo que pensamos y sentimos (Dupont, 1980). Lógicamente, la cultura individualista en desarrollo se traslada a los mensajes publicitarios. Por ello, en los ochenta, se puede decir de una pluma que "significa la perfecta expresión de carácter, personalidad e individualidad" (MontBlanc, 1986).

Esa intensidad de los mensajes que acentúan los estilos y las formas de ser encaja adecuadamente con la gran década de la construcción de imágenes de marca, constituidas como formas de carácter. Habrá plumas tan exclusivas y exquisitas como una obra de arte, de corte clásico y elegante, plumas muy personales o una pluma que sea: "atrevida, con carácter. Clásica, única. Con estilo, genial, sensible, noble, tiene competencia. Pero no rival. Irresistible" (Waterman, 1979). Ya está segmentándose el mercado en todos los nichos posibles, se están caracterizando -a la vez que construyendo- cuerpos de personalidad a los que dirigir una determinada 
imagen de marca. Por tanto, el esfuerzo de las empresas y sus campañas será tratar de reunir en la imagen de marca los caracteres de una determinada posición social.

Esta constitución de imágenes de marca es lo que explica que aparezca el mundo de la perfumería metido a la venta de plumas. Se trata de reunir aquello que te acompaña siempre, de ser fiel a la imagen de una marca. Perfume, mechero, pluma y bolígrafo (luego aparecerán la cartera, el reloj, el llavero...) te configuran y marcan. Las marcas que se presentan así desde otro espacio del mercado con una imagen ya configurada no necesitan nada más que su propio significante (Dior, 1977; Cartier, 1981 y 1984; Flaminaire, 1981).

Otro aspecto que merece ser recogido es el de las nuevas tecnologías: por ejemplo, la gama de titanio de MontBlanc (1986), material desarrollado para enfrentarse a las más difíciles condiciones en el espacio. Sin embargo, el papel de la tecnología puede ser más complejo puesto que el objetivo sólo declarado explícitamente en algunas casos (Parker, 1989) es reunir la mayor sofisticación técnica posible con la condición artesanal de principios de siglo. Incluir la tecnología punta y «permanecer estéticamente igual». Para hacerse deseada para el hombre de negocios al que se dirige la pluma simboliza la posibilidad de superar sus propias contradicciones. Superar la contradicción de un empresario que expresa su imagen como empreario de principios de siglo pero que su contexto es el del dinero fácil y la gran organización de finales de los ochenta.

Por tanto, se podría decir que hay un sector homogéneo de población al que se dirigen casi todas las marcas. Siempre hay sectores marginales, como el que busca la elegancia de Dunhill (1982) o los jóvenes (Inoxcrom, 1986). Apenas hay todavía grandes diferencias entre las imágenes de las diferentes marcas. Todas buscan un carácter, buscan introducir la sensibilidad y la personalidad en el mundo frío, impersonal e inexpresivo de la empresa. Para las relaciones personales, para los 
grandes momentos de los negocios debe haber una pluma, y una pluma que facilite la fluidez del carácter. Las plumas son fieles, siempre junto a su dueño y con alma propia: "Perciba su interior. Es el alma de Parker" (1984).

En resumen, se consolidan dos grandes líneas en estas décadas:

- Arte y perfección, exclusividad. Se reúnen artesanía y sofisticación técnica.

- Personalidad, expresión del carácter. Se reúne el individualismo más radical con la completa fetichización del objeto. No están los demás y no hay nada más que una pluma. Se trata de dar buena imagen, de encontrar el mejor camino para brillar, para sobresalir, para mostrarnos más sensibles, nobles, íntegros que los demás, aquéllos que han desaparecido.

\section{AÑOS NOVENTA: TIEMPO DE HISTORIAS PERSONALES}

Este último bloque de anuncios podemos dividirlo en dos grandes grupos:

1. Un primer cuerpo de anuncios estaría representado idealmente por las marcas Parker y Waterman. Estos son realmente el espacio en el que aparecen las historias personales. En esta década se mantienen muchas constantes respecto a los años anteriores. Sigue siendo condición necesaria de toda estilográfica que reuna la perfección técnica con la elaboración a mano. Debe ser un diseño exclusivo con un plumín cortado a mano con discos tan finos como un cabello en un proceso que dure varios días (Parker, 1997). Pero a la vez debe tener materiales que resistan la presión de los 13.000 metros de altura donde fluyen con más ligereza las ideas brillantes del 
hombre de negocios (Waterman, 1993). Y además en esa tercera dimensión presente desde años atrás la estilográfica debe ser una obra de arte, debe ser bella, hermosa con un toque mágico que a su vez convierta en genial lo que se realiza y expresa con ella.

En los años anteriores que hemos comentado era el consumidor quien imprimía el toque personal con la pluma adecuada. Pero el producto mantenía todavía un carácter abierto, multidimensional aunque, sin duda, estaba ya ligado a estilos de vida y formas de expresividad. La diferencia que introducen los años noventa es que se reducen las llamadas a que el consumidor imprima su marca, a que imponga su estilo, a que exprese su personalidad a través de la pluma. Es decir, si en los setenta y ochenta la estilográfica era un camino para expresar la personalidad noble, especial y sensible del consumidor, en los años noventa el producto ha asumido ya la personalidad y necesita de un texto para contarla. Parker (1984 y 1987) se había adelantado en cierta medida constituyendo su producto como un producto con alma, pero era un alma fría estrictamente rodeada de características técnicas, lujo, artesanía y precisión.

El proceso de degradación publicitaria, ese proceso de significantización, implica que se vuelve a buscar el estímulo entendido como en la teoría conductivista. No hay símbolos concretos -completos- que remitan a una posición social compleja. Los significantes son directos y llaman a la identificación inmediata, mecánica: "¿Qué Waterman eres tú?" (Waterman, 1994). Ahora cada pluma lleva completa la historia de una vida, el consumidor sólo tiene que adscribirse a lo que le corresponde.

Otra diferencia es que reaparecen las personas, la publicidad se hace menos fría y abstracta, pero no se hace concreta, se hace singular, individual y específica. Si en las dos décadas anteriores no encontramos, salvo en algunos anuncios marginales ya comentados (Dunhill, 1982; Inoxcrom, 1986), ni una sola persona e incluso nada más 
allá del propio objeto fetichizado pluma, los años noventa introducen una gran riqueza de nuevas imágenes, contextos y personas. Personas que aparecen como expresiones de lo que rodea a la forma de vida de aquellos consumidores a los que se dirige: o bien son personas a superar, con las que enfrentarse, frente a las que hay que salir airoso (Parker, 1990); o bien son las personas cercanas, del círculo íntimo, sea la pareja, sea el jefe (Waterman, 1990; Parker, 1992).

Hemos prescindido de la imagen de la mujer que surge de la publicidad de este producto. Ya hemos señalado que se trata de un producto estrictamente masculino. Si había publicidad dirigida a la mujer era para que hiciera un regalo al hombre. En los años ochenta y noventa va apareciendo tímidamente una publicidad dirigida a que la mujer utilice la pluma. Es el caso, por ejemplo, de Parker (1990) que combina una campaña paralela con un anuncio dirigido al hombre (con letra masculina, coche deportivo, competitividad, enfrentamiento, seguridad,...) y uno dirigido a la mujer (con letra femenina, íntimo, tierno, en su papel de madre,...). Pero la timidez con que se asoma la mujer, el hecho de que tenga un lugar, aunque siga siendo subordinado, puede convivir con la imagen de una mujer que adora al hombre y a ello se limita. En este último caso la pluma se convierte en un regalo para expresar adoración en un texto que carece de desperdicio (Waterman, 1990). Los roles están bien repartidos, el hecho de que la mujer de Parker se ocupe de su hija encaja con que el hombre de Cross se ocupe de su hijo (Cross, 1991, 1992). El hombre es el que mantiene la dinastía, y la pluma pretende llegar a asociarse a la historia de la familia (masculina).

Este primer cuerpo de anuncios se orienta a un sector relativamente joven, todavía enamorado de la vida, adicto al trabajo (Parker, 1992), dinámico y deportivo (Parker, 1990 y 1992), de éxito creciente (Waterman, 1992). Por ello, la elección del modelo de pluma "es una elección claramente romántica" (Parker, 1993) como las que se toman en la vida personal. Evidentemente hay una cierta gradación entre las diferentes 
marcas. Si ordenáramos de menor a mayor por edad y seguridad de la posición económica la gradación de las marcas sería: Parker, Waterman, Cross.

2. Un segundo cuerpo de anuncios lo constituyen Sheaffer y MontBlanc. En ellos apenas hay palabras. El extremo es el de Sheaffer donde ni siquiera hay fondo, donde no hay nada más que el significante de la marca y el producto cuya calidad y distinción se reflejan sin palabras. MontBlanc sí realiza variaciones construyendo los anuncios como cuadros surrealistas e insistiendo en el carácter artístico de la escritura. Esta insistencia en la escritura en la que se insertan el modelo de pluma utilizado por Hemingway (MontBlanc, 1992) o citas de Wilde (MontBlanc, 1994) es una clave de los diferentes tipos de consumidores a los que apunta este segundo cuerpo de anuncios. Lo que distinguiría a los consumidores de estas marcas no sería simplemente diferencias profesionales o diferencias de renta sino su carácter ilustrado. En ambos cuerpos de anuncios la pluma aparece como obra de arte que debe ser apreciada, pero sólo aquí es el mismo anuncio, el conjunto de significantes asociados a la marca, los que aparecen a su vez como una obra de arte.

Al crear toda una gama de productos derivados pero asociados (agenda, reloj, cartera, llavero,...) MontBlanc (1997) busca sostener a un cuerpo fiel y estable de clientes mediante una imagen de marca sólida. Un caso paradigmático del reflejo publicitario de la dualización social dentro de la clase alta y media alta que se reabre en los años ochenta y cristaliza en los noventa lo constituye esta misma imagen de marca construida por MontBlanc. Como reconoce su vicepresidente (El País, 01/02/98), a partir de 1986 cambiaron radicalmente de estrategia. Si hasta entonces más de dos tercios de los ingresos de la compañía provenían de la venta de plumas en masa (modelos siempre caros pero relativamente) a partir de esa fecha la compañía se concentró en la fabricación de plumas de lujo llevadas hasta el extremo: la joya de todas ellas es la pluma Solitarie Royal, la estilográfica más cara del mundo, de oro macizo y con 4.810 diamantes -la altura del Mont Blanc- montados a mano, 
con un precio de 15 millones de pesetas.

La marca tomó conciencia de la imposibilidad de abarcar estratos amplios del mercado debido, por un lado a la creciente heterogeneidad de los demandantes, pero a mi entender de forma más importante debido a la progresiva degradación de los estratos medios. Es difícil explicar esta reciente elitización sin acudir a alguna hipótesis sobre la crisis de las clases medias funcionales a lo largo de los años ochenta $\mathrm{y}$, especialmente, a lo largo de la segunda mitad.

3. Un tercer cuerpo de anuncios está constituido por una variedad de marcas la mayoría de ellas no especializadas en plumas. De hecho, con las excepciónes de Dupont (1997) -que asemeja su publicidad a la del segundo grupo analizado antes- o Pelikan (1990, 1996 y 1997), todas tienen asociada la imagen de sus respectivos productos fundamentales y tratan de ocupar en las plumas estilográficas lo que MontBlanc trata de hacer con agendas, carteras,... Se trata de aprovechar la imagen de marca para aumentar la variedad de productos. Así se reúnen: el mundo del diseño y el dibujo (Rotring, 1991 y 1996; Faber-Castell, 1996 y 1997); el mundo del perfume (Christian Dior, 1994 y 1996); el mundo de la joyería (Élysée, 1992); o el mundo personal de Alfred Dunhill (Dunhill, 1997).

\section{APÉNDICE: LAS INTRUSIONES DE LA PLUMA}

Aquí sólo pretendemos recoger unos cuantos ejemplos de algo que es muy común: la intrusión del objeto pluma en la publicidad de otros productos. Incluir esto no tiene más sentido que el de considerar que ayuda a comprender y contextualizar el mundo asociado a la pluma, y con ello a comprender los significantes de la publicidad utilizada por la pluma. De hecho, estos anuncios son interpretaciones de lugares 
donde el consumidor tendría asociada siempre una pluma estilográfica: firmas de contratos (banco -Citibank, 1992-, seguros -Axa, 1990-), agendas electrónicas (Casio, 1997), teléfonos móviles (Moviline, 1996), firma de mensajes personales (Olivetti, 1990), viajes (Stuyvesant, 1992). Esos mundos que son creados progresivamente desde la irrupción del bolígrafo y que ya no aparecen en la publicidad de los noventa porque se dan por sentado, porque ya forman parte de los usos. 